\title{
Pengaruh Geometri Infill terhadap Kekuatan Tarik Spesimen Uji Tarik ASTM D638 Type IV Menggunakan Filamen PLA+ Sugoi
}

\author{
Zaldy Sirwansyah Suzen, Hasdiansah* \\ Teknik Mesin, Politeknik Manufaktur Bangka Belitung \\ Kawasan Industri Air Kantung, Bangka, 33211, Telp: 0717-93586, Fax: 0717-93585 \\ *E-mail: syahdika99@gmail.com
}

Diterima: 25-01-2021; Direvisi: 08-08-2021; Dipublikasi: 27-08-2021

\begin{abstract}
Abstrak
Pengaturan parameter proses 3D Printing berteknologi Fused Deposition Modelling (FDM) sangat mempengaruhi kualitas produk cetak baik dalam hal akurasi dimensi, surface roughness, dan kekuatan tariknya. Dua material yang paling sering digunakan para praktisi 3D Printing adalah PLA dan ABS masih memerlukan pengaturan parameter proses pada slicing software untuk menghasilkan produk cetak paling kuat ditinjau dari kuat tariknya. Penelitian ini memvariasikan bentuk geometri infill yang tersedia pada Ultimaker Cura 4.8.0 dalam mencetak spesimen uji tarik ASTM D638 Type IV. Ada 13 (tiga belas) bentuk infill yang digunakan dengan infill density 100\%. Ada 3 (tiga) variasi nozzle temperature yaitu $205^{\circ} \mathrm{C}, 215^{\circ} \mathrm{C}$, dan $225^{\circ} \mathrm{C}$. Parameter proses yang tetap seperti layer thickness $0,2 \mathrm{~mm}$, printing speed $50 \mathrm{~mm} / \mathrm{s}$, travel speed $100 \mathrm{~mm} / \mathrm{s}$, dan bed temperature $60^{\circ} \mathrm{C}$. Spesimen uji tarik dicetak masing-masing tiga buah pada 39 (tiga puluh sembilan) eksperimen dan rata-rata hasil uji tarik dihitung kemudian selanjutnya dianalisis. Nilai kekuatan tarik tertinggi diperoleh pada pengaturan nozzle temperature $205^{\circ} \mathrm{C}$ dengan bentuk infill concentric atau terdapat pada eksperimen nomor 9 dengan nilai 32,40 MPa. Sedangkan nilai kekuatan tarik diperoleh pada pengaturan nozzle temperature $225^{\circ} \mathrm{C}$ dan dengan bentuk infill cross atau pada eksperimen nomor 37 dengan nilai 19,10 MPa. Sehingga dapat disimpulkan bahwa bentuk geometri infill pada proses 3D Printing FDM sangat mempengaruhi kekuatan tarik produk cetak.
\end{abstract}

Kata kunci: concentric; cross; 3D Printing; infill; PLA+

\begin{abstract}
$3 D$ Printing process parameter settings with Fused Deposition Modeling (FDM) technology greatly affect the quality of print products in terms of dimensional accuracy, surface roughness, and tensile strength. The two materials most often used by $3 D$ Printing practitioners, PLA and ABS, still require setting process parameters in the slicing software to produce the strongest printed product in terms of tensile strength. This study varied the infill geometric shapes available in Ultimaker Cura 4.8.0 in printing the ASTM D638 Type IV tensile test specimen. There are 13 (thirteen) forms of infill which are used with infill density of $100 \%$. There are 3 (three) variations of the nozzle temperature, namely $205^{\circ} \mathrm{C}, 215^{\circ} \mathrm{C}$, and $225^{\circ} \mathrm{C}$. Fixed process parameters such as layer thickness $0.2 \mathrm{~mm}$, printing speed 50 $\mathrm{mm} / \mathrm{s}$, travel speed $100 \mathrm{~mm} / \mathrm{s}$, and bed temperature $60^{\circ} \mathrm{C}$. The tensile test specimens were printed three in each of the 39 (thirty nine) experiments and the mean of the tensile test results was calculated and then analyzed. The highest tensile strength value is obtained at the nozzle temperature setting of $205^{\circ} \mathrm{C}$ with the concentric infill form or found in experiment number 9 with a value of $32.40 \mathrm{MPa}$. While the tensile strength value is obtained at the nozzle temperature setting of $225^{\circ} \mathrm{C}$ and in the form of an infill cross or in experiment number 37 with a value of 19.10 $M P a$. So it can be concluded that the geometric shape of the infill in the 3D Printing FDM process greatly affects the tensile strength of printed products.
\end{abstract}

Keywords: concentric; cross; $3 D$ Printing; Infill PLA +

\section{Pendahuluan}

Dalam upaya pengembangan suatu kualitas suatu produk untuk mendapatkan hasil yang baik, maka sangat diperlukan sebuah teknologi. Salah satunya adalah penggunaan Mesin 3D Printing yang merupakan teknologi yang sedang berkembang saat ini pada industri manufaktur. Prinsip kerja 3D Printing adalah dengan cara menggunakan metode penambahan material dalam membuat produk yang sering disebut proses Additive manufacturing. Dimana Additive Manufacturing telah banyak diterapkan di berbagai industri, termasuk konstruksi, kesehatan, prototyping dan biomekanik [1]. Produk inilah yang diupayakan agar dapat menggantikan material logam pada umumnya untuk pembuatan spare part 
mesin ataupun peralatan yang membutuhkan biaya yang lebih ekonomis mudah dalam pembuatannya yang bisa menggantikan spare part bahan logam.

Dua jenis material yang paling sering digunakan yaitu material Polylactic acid or polylactide (PLA) dan Acrylonitrile butadiene styrene (ABS) [2], karena teknologi 3D Printing FDM mampu membuat produk duplikat dengan akurat salah satunya menggunakan material ABS [3]. Adapun Material PLA merupakan salah satu material berjenis thermoplastic polymer yang paling banyak digunakan untuk pembuatan model tiga dimensi. Selain mempunyai titik leleh yang rendah yaitu pada temperatur $190^{\circ} \mathrm{C}$ [4] material ini juga mempunyai sedikit bau jika dibandingkan dengan jenis ABS [5] yang memiliki temperatur $240^{\circ} \mathrm{C}$ [6]. Material PLA yang memiliki sifat tarik dan lentur telah banyak diteliti menggunakan orentasi posisi tegak menghasilkan kinerja mekanik paling rendah, sedangkan orientasi posisi tepi dan rata menghasilkan kekuatan dan kekakuan yang tinggi [7].

Penelitian menggunakan metode Fused Deposition Modeling (FDM) material Polimeric ULTEM 9085 dengan desain percobaan faktorial penuh menggunakan parameter air gap,raster width, raster angle, contour number and contour width, hasil yang didapat yaitu pada parameter Raster angle memiliki pengaruh tinggi dengan menghasilkan kekuatan tarik terendah sekitar $30 \mathrm{MPa}$, sedangkan $87 \mathrm{MPa}$ untuk kekuatan tarik tertinggi [8].

Pada penelitian yang sudah dilakukan pada produk menggunakan material PLA dengan orientasi posisi objek horizontal memiliki kualitas dimensi yang paling baik. Jumlah kesalahan akurasi material ini tidak melebihi $1 \mathrm{~mm}$ pada setiap layer. Sedangkan material ABS dengan posisi orientasi objek vertikal dan tebal layer sebesar $0,10 \mathrm{~mm}$ menghasilkan kekuatan tegangan tarik yang terkecil sebesar 8,62 MPa dan material PLA dengan orientasi posisi objek horizontal dengan dan tebal layer sebesar 0,40 mm menghasilkan kekuatan tegangan tarik terbesar 35,57 Mpa [9].

Pada penelitian sebelumnya yang menggunakan material PLA+ Material yang digunakan adalah filamen PLA+ Esun dengan diameter $1,75 \mathrm{~mm}$ dengan variasi parameter nozzle temperature yaitu $205^{\circ} \mathrm{C}, 215^{\circ} \mathrm{C}$ dan $225^{\circ} \mathrm{C}$, layer thickness 0,2 , bed temperature $60^{\circ} \mathrm{C}$, travel speed 100 , printing speed 50, dengan infill type yaitu Grid, Lines, Triangles, Tri Hexagon, Cubic, Cubic Subdivision, Octet, Quarter Qubic, Concentric, Zig Zag, Cross, Cross 3D dan Gyroid, telah menghasilkan kekuatan tarik tertinggi yaitu 43,20 Mpa dengan parameter temperature nozzle $215^{\circ} \mathrm{C}$ pada Infill Type Concentric. Sedangkan nilai kekuatan tarik terendah yaitu 24,50 Mpa pada temperature nozzle $205^{\circ} \mathrm{C}$ dengan Infill Type Cross [10]. Penelitian yang telah dilakukan terhadap material PLA Food Grade menunjukkan pengaturan parameter terbaik terhadap akurasi tinggi spesimen uji yaitu nozzle temperature $\left(185^{\circ} \mathrm{C}\right)$, layer thickness $(0,20 \mathrm{~mm})$, printing speed $(40 \mathrm{~mm} / \mathrm{s})$, infill rate $(8 \%)$, dan temperature based plate $\left(40{ }^{\circ} \mathrm{C}\right)$ [11]. Setting parameter yang menghasilkan kekasaran permukaan terbaik dengan nilai 3,321 $\mu \mathrm{m}$ dengan menggunakan filamen ST. PLA adalah 0,10 mm untuk layer thickness, $40 \mathrm{~mm} / \mathrm{s}$ untuk printing speed, $190^{\circ} \mathrm{C}$ untuk nozzle temperature, $45^{\circ}$ untuk orientation, $110 \%$ untuk flowrate dan $40 \%$ untuk cooling speed [12]. Tiga parameter proses digunakan dalam penelitian ini, temasuk jenis filamen, infill density, dan infill pattern. Berdasarkan hasil pengujian kuat tarik spesimen uji, bahwa faktor yang paling berpengaruh adalah infill pattern, penelitian ini menggunakan Full Factorial [13]. Penelitian terhadap filamen PLA dengan pengaturan bed temperature $60^{\circ} \mathrm{C}$, nozzle temperature $200^{\circ} \mathrm{C}$, dan printing speed $80 \mathrm{~mm} / \mathrm{s}$. Type infill bentukl line dengan densitas $100 \%$ menunjukkan bahwa semakin besar nozzle yang digunakan memberikan pengaruh terhadap kuat tarik, tetapi tidak meningkat signifikan atau tidak meningkat secara linear [14]. Tujuh variasi diameter nozzle, $0,2 \mathrm{~mm}, 0,3 \mathrm{~mm}, 0,4 \mathrm{~mm}$, 0,5mm, 0,6mm 0,8mm, dan 1mm telah digunakan untuk mencetak spesimen uji tarik standar PN-EN ISO 527:1998 menunjukkan bahwa diameter nozzle $0,5 \mathrm{~mm}$ menghasilkan kuat tarik tertinggi yaitu $1,93 \mathrm{kN}$ [15]. Berdasarkan penjelasan di atas, penelitian ini dilakukan untuk membandingkan dan mengetahui hasil dari pengaruh infill tehadap kuat tarik spesimen uji Tarik ASTM D638 type IV menggunakan material PLA+ Sugoi. 


\section{Metode Penelitian}

\subsection{Objek Penelitian}

Objek penelitian adalah menggunakan material filamen PLA+ Sugoi dengan diameter 1,75 mm yang akan dicetak pada mesin 3D FDM model Prusa dengan menggunakan nozzle berukuran 0,4 $\mathrm{mm}$ dengan parameter parameter tersebut yaitu temperature nozzle $\left(205^{\circ} \mathrm{C}, 215^{\circ} \mathrm{C}, 225^{\circ} \mathrm{C}\right)$, layer Thickness $0,2 \mathrm{~mm}$, Temperature Bed $60^{\circ} \mathrm{C}$, Travel Speed 100 $\mathrm{mm} / \mathrm{s}$, Printing Speed $50 \mathrm{~mm} / \mathrm{s}$, infill precentase 100\% dan infill Type (Grid, Lines, Triangles, Tri Hexagon, Cubic, Cubic Subdivision, Octet, Quarter Qubic, Concentric, Zig Zag, Cross, Cross 3D dan Gyroid).

\subsection{Metode Yang Digunakan}

Metode yang digunakan pada penelitian ini adalah dengan melakukan studi literatur untuk mendapatkan nilai tertinggi dan terendah dari parameter 39 spesimen sampel yang dicetak pada mesin 3D Printing kemudian dilakukan pengujian tarik. Setelah data pengujian tarik diperoleh, selanjutnya akan dilakukan analisa menggunakan tabel kemudian dari hasil yang yang diperoleh akan terdapat nilai tertinggi berdasarkan hasil analis data. Kemudian akan dibuat simpulan dalam tampilan grafik analisa.

\subsection{Alat dan Bahan}

Alat yang digunakan untuk mencetak spesimen pada penelitian ini yaitu mesin 3D Printer FDM Anet ET4 dengan printing volums XYZ $220 \mathrm{~mm} \times 220 \mathrm{~mm} \times 250 \mathrm{~mm}$ yang ditunjukan pada Gambar 1. Sedangkan bahan yang digunakan sebagai media uji yaitu Material filamen PLA+ Sugoi dengan diameter 1,75 mm.

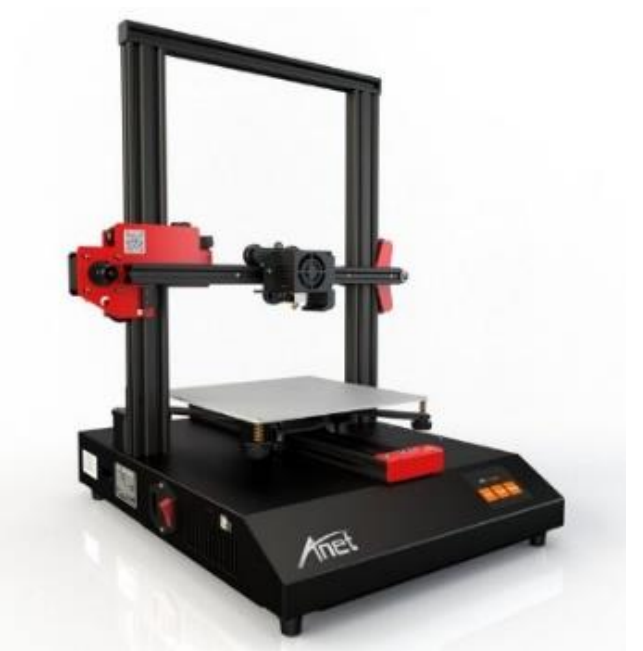

Gambar 1. Mesin 3D Printing FDM Anet ET4

Untuk proses selanjutnya akan dilakukan pencetakan sample material sesuai dengan jumlah yang akan dianalisa dan memiliki ukuran berdasarkan standar ASTM D638 TYPE IV yang ditunjukkan pada Gambar 3. Proses pencetakan menggunakan Software Slicer software Ultimaker Cura 4.4.0 yang telah dipasangkan di komputer yang digunakan untuk mendapatkan G-Code yang digunakan pada mesin $3 D$ Printer. Selanjutnya adalah proses pengujian di Mesin Uji Tarik Zwick Roell model 2012 BT2-FR020TH.A50 yang ditunjukkan pada Gambar 2. 


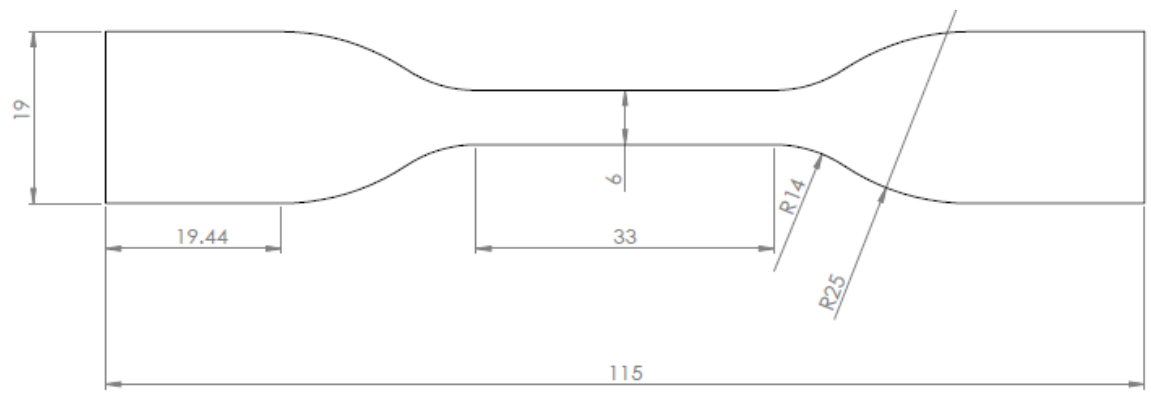

Gambar 2. Dimensi Material standar ASTM D638 TYPE IV

\subsection{Jenis dan Sumber Data}

Jenis data yang diperlukan dalam melakukan penelitian ini yaitu spesifikasi mesin 3D Printer yang akan digunakan untuk mencetak produk yang akan diuji tarik, karaketristik filamen yang digunakan, nilai dari setiap parameter proses yang akan diuji serta hasil uji tarik dari produk yang berbentuk standar ASTM D638 TYPE IV.

\subsection{Langkah-langkah Penelitian}

Pada tahapan ini penentuan parameter awal ditentukan berdasarkan studi pustaka dan rekomendasi pabrik pembuat filamen PLA+Sugoi. Selanjutnya proses kalibrasi mesin 3D Printer harus dilakukan untuk mendapatkan kedataran pada meja cetak. Pembuatan 3D objek dengan menggunakan CAD dan file gambar 3D selanjutnya disimpan dalam format STL (*.stl). Selanjutnya file STL (*.stl). tersebut diolah pada software slicing (Ultimaker Cura 4.4.0), dan pada tahap ini objek 3D akan dibuat layer by layer dengan variasi parameter nozzle temperature, layer thickness, bed temperature, travel speed, printing speed, infill type yang akan ditentukan pada software Ultimaker Cura 4.4.0. Tahap ini juga merupakan penentuan parameter proses dan penentuan level tiap parameter juga ditentukan berdasarkan studi pustaka dan rekomendasi pabrik pembuat filamen PLA+. Selanjutnya akan dilakukan penentuan dimensi dan bentuk 3D objek cetak berdasarkan standar ASTM D638 TYPE IV kemudian material akan dicetak satu persatu sebanyak 39 sample menggunakan mesin 3D Printer seperti yang ditunjukkan pada Gambar 3.

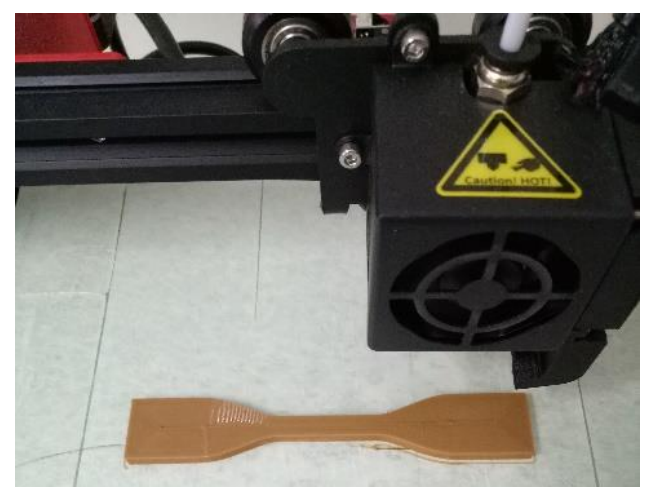

Gambar 3. Material Cetak

\subsection{Penentuan Faktor dan Level Eksperimen}

Pemilihan parameter proses yang berupa faktor dan level eksperimen berdasarkan studi pustaka yang telah dilakukan. Filament yang akan dijadikan sebagai bahan baku penelitian telah adalah PLA+ Sugoi. Spesimen uji menggunakan parameter nozzle temperature dengan 3 level suhu yaitu $205^{\circ} \mathrm{C}, 215^{\circ} \mathrm{C}$, dan $225^{\circ} \mathrm{C}$, layer thickness, bed temperature, travel speed, printing speed dengan nilai yang konstan dan 13 infill type sehingga menghasilkan 39 specimen untuk diuji seperti yang ditunjukkan pada Tabel 1. 
Zaldy Sirwansyah Suzen dkk /Jurnal Rekayasa Mesin

p-ISSN: 1411-6863, e-ISSN: 2540-7678

Vol.16|No.2|140-147|Agustus|2021

Tabel 1. Nilai Level Parameter yang Diuji

\begin{tabular}{ccccccc}
\hline $\begin{array}{c}\text { Temperatu } \\
\text { re Nozzle } \\
\left({ }^{\circ} \mathbf{C}\right)\end{array}$ & $\begin{array}{c}\text { Layer } \\
\text { Thickness } \\
(\mathbf{m m})\end{array}$ & $\begin{array}{c}\text { Tempera } \\
\text { ture Bed } \\
\left({ }^{\circ} \mathbf{C}\right)\end{array}$ & $\begin{array}{c}\text { Travel } \\
\text { Speed } \\
(\mathbf{m m} / \mathbf{s})\end{array}$ & $\begin{array}{c}\text { Printing } \\
\text { Speed } \\
(\mathbf{m m} / \mathbf{s})\end{array}$ & $\begin{array}{c}\text { Infill } \\
\text { percentase } \\
(\%)\end{array}$ & Infill Type \\
\hline $\begin{array}{c}205,215, \\
225\end{array}$ & 0,2 & 60 & 100 & 50 & 100 & $\begin{array}{c}\text { grid, lines, triangles, tri } \\
\text { hexagon, cubic, cubic } \\
\text { subdivision, octet, quarter } \\
\text { qubic, concentric, zig zag, } \\
\text { cross, cross 3D, gyroid }\end{array}$ \\
\hline
\end{tabular}

Berdasarkan Tabel 1 yang telah ditentukan maka akan dicetak spesimen sebanyak 39 sperimen yang berbentuk sesuai standar ASTM D638 TYPE IV, kemudian akan dilakukan analisa hasil yang akan diperoleh dari pengujian tarik. Nilai tiap parameter akan di-input ke mesin 3D Printer dan akan dilakukan pencetakan. Hasil cetakan akan dilakukan pengujian tarik menggunakan mesin uji tarik Merk Zwick Roell untuk mengetahui nilai tertinggi dan terendah dari spesimen yang dicetak berdasarkan data dan bentuk-bentuk infill yang dipilih seperti yang ditunjuk pada Gambar 3 .

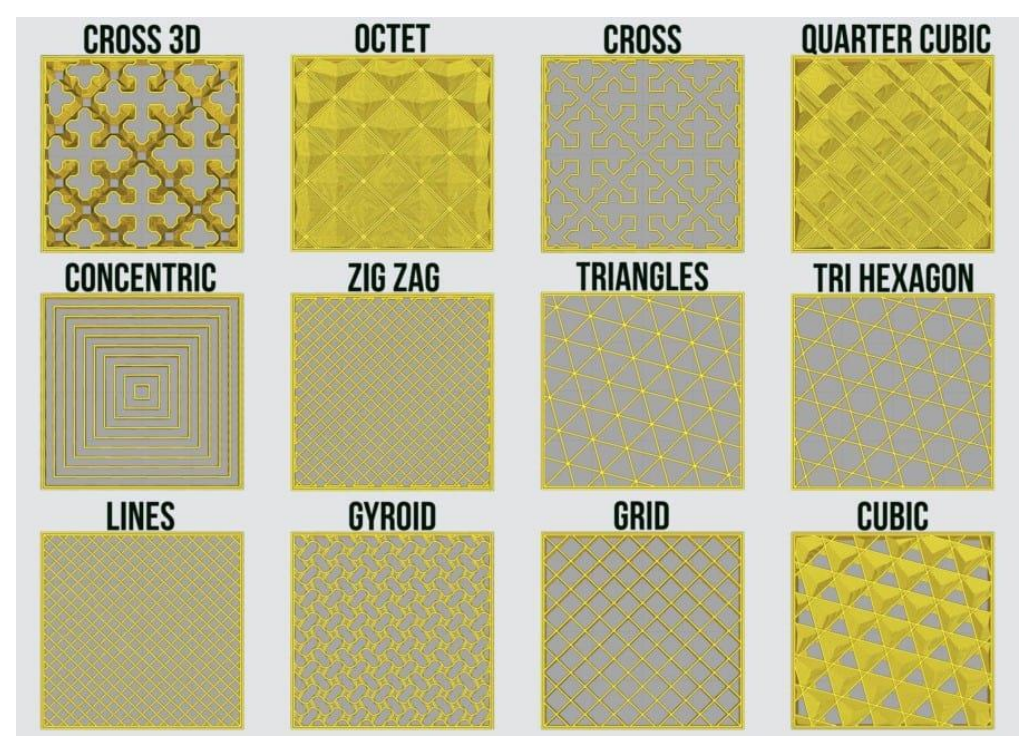

Gambar 3. Bentuk-bentuk Infill Pada Ultimaker Cura [16]

\subsection{Pengujian Tarik Spesimen}

Parameter- parameter geometri proses yang diatur pada slicing software menunjukkan hasil kekuatan tarik spesimen uji ASTM D638 Type IV yang bervariasi. Hasil pengujian tarik spesimen uji ditunjukkan pada Tabel 2.

Tabel 2. Nilai Hasil Pengujian Tarik Spesimen Uji ASTM D638 Type IV

\begin{tabular}{|c|c|c|c|c|c|c|c|c|}
\hline $\begin{array}{l}E X P \\
\text { No. }\end{array}$ & $\begin{array}{c}\text { Temperatu } \\
\text { re Nozzle } \\
\left({ }^{\circ} \mathrm{C}\right) \\
\end{array}$ & $\begin{array}{c}\text { Layer } \\
\text { Thicknes } \\
\text { s }(\mathbf{m m}) \\
\end{array}$ & $\begin{array}{c}\text { Temperatu } \\
\text { re Bed } \\
\left({ }^{\circ} \mathrm{C}\right) \\
\end{array}$ & $\begin{array}{c}\text { Travel } \\
\text { Speed } \\
(\mathrm{mm} / \mathrm{s})\end{array}$ & $\begin{array}{c}\text { Printing } \\
\text { Speed } \\
(\mathrm{mm} / \mathrm{s})\end{array}$ & $\begin{array}{c}\text { Infill } \\
\text { percentase } \\
(\%)\end{array}$ & infill Type & $\begin{array}{c}\text { Hasil Uji } \\
\text { Tarik } \\
\text { (Mpa) } \\
\end{array}$ \\
\hline 1 & 205 & 0.2 & 60 & 100 & 50 & $100 \%$ & Grid & 20,50 \\
\hline 2 & 205 & 0.2 & 60 & 100 & 50 & $100 \%$ & lines & 20,20 \\
\hline 3 & 205 & 0.2 & 60 & 100 & 50 & $100 \%$ & Triangles & 20,70 \\
\hline 4 & 205 & 0.2 & 60 & 100 & 50 & $100 \%$ & $\begin{array}{c}\text { Tri } \\
\text { Hexagon }\end{array}$ & 19,80 \\
\hline 5 & 205 & 0.2 & 60 & 100 & 50 & $100 \%$ & Cubic & 22,00 \\
\hline 6 & 205 & 0.2 & 60 & 100 & 50 & $100 \%$ & $\begin{array}{c}\text { Cubic } \\
\text { Subdivisio } \\
\mathrm{n}\end{array}$ & 20,20 \\
\hline
\end{tabular}


Zaldy Sirwansyah Suzen dkk /Jurnal Rekayasa Mesin p-ISSN: 1411-6863, e-ISSN: 2540-7678 Vol.16|No.2|140-147|Agustus|2021

\begin{tabular}{|c|c|c|c|c|c|c|c|c|}
\hline $\begin{array}{l}E X P \\
. N o .\end{array}$ & $\begin{array}{c}\text { Temperatu } \\
\text { re Nozzle } \\
\left({ }^{\circ} \mathrm{C}\right)\end{array}$ & $\begin{array}{c}\text { Layer } \\
\text { Thicknes } \\
s(\mathbf{m m})\end{array}$ & $\begin{array}{c}\text { Temperatu } \\
\text { re Bed } \\
\left({ }^{\circ} \mathrm{C}\right)\end{array}$ & $\begin{array}{l}\text { Travel } \\
\text { Speed } \\
(\mathrm{mm} / \mathrm{s})\end{array}$ & $\begin{array}{c}\text { Printing } \\
\text { Speed } \\
(\mathrm{mm} / \mathrm{s}) \\
\end{array}$ & $\begin{array}{c}\text { Infill } \\
\text { percentase } \\
(\%)\end{array}$ & infill Type & $\begin{array}{c}\text { Hasil Uji } \\
\text { Tarik } \\
\text { (Mpa) }\end{array}$ \\
\hline 7 & 205 & 0.2 & 60 & 100 & 50 & $100 \%$ & Octet & 20,80 \\
\hline 8 & 205 & 0.2 & 60 & 100 & 50 & $100 \%$ & $\begin{array}{l}\text { Quarter } \\
\text { Qubic }\end{array}$ & 21,70 \\
\hline 9 & 205 & 0.2 & 60 & 100 & 50 & $100 \%$ & Concentric & 32,40 \\
\hline 10 & 205 & 0.2 & 60 & 100 & 50 & $100 \%$ & Zig Zag & 20,70 \\
\hline 11 & 205 & 0.2 & 60 & 100 & 50 & $100 \%$ & Cross & 19,40 \\
\hline 12 & 205 & 0.2 & 60 & 100 & 50 & $100 \%$ & Cross 3D & 20,80 \\
\hline 13 & 205 & 0.2 & 60 & 100 & 50 & $100 \%$ & Gyroid & 26,90 \\
\hline 14 & 215 & 0.2 & 60 & 100 & 50 & $100 \%$ & Grid & 25,20 \\
\hline 15 & 215 & 0.2 & 60 & 100 & 50 & $100 \%$ & lines & 21,80 \\
\hline 16 & 215 & 0.2 & 60 & 100 & 50 & $100 \%$ & Triangles & 20,50 \\
\hline 17 & 215 & 0.2 & 60 & 100 & 50 & $100 \%$ & $\begin{array}{c}\text { Tri } \\
\text { Hexagon }\end{array}$ & 22,00 \\
\hline 18 & 215 & 0.2 & 60 & 100 & 50 & $100 \%$ & Cubic & 20,20 \\
\hline 19 & 215 & 0.2 & 60 & 100 & 50 & $100 \%$ & $\begin{array}{c}\text { Cubic } \\
\text { Subdivisio } \\
n\end{array}$ & 21,10 \\
\hline 20 & 215 & 0.2 & 60 & 100 & 50 & $100 \%$ & Octet & 20,40 \\
\hline 21 & 215 & 0.2 & 60 & 100 & 50 & $100 \%$ & $\begin{array}{l}\text { Quarter } \\
\text { Qubic }\end{array}$ & 20,50 \\
\hline 22 & 215 & 0.2 & 60 & 100 & 50 & $100 \%$ & Concentric & 31,70 \\
\hline 23 & 215 & 0.2 & 60 & 100 & 50 & $100 \%$ & Zig Zag & 22,00 \\
\hline 24 & 215 & 0.2 & 60 & 100 & 50 & $100 \%$ & Cross & 19,80 \\
\hline 25 & 215 & 0.2 & 60 & 100 & 50 & $100 \%$ & Cross 3D & 21,20 \\
\hline 26 & 215 & 0.2 & 60 & 100 & 50 & $100 \%$ & Gyroid & 27,00 \\
\hline 27 & 225 & 0.2 & 60 & 100 & 50 & $100 \%$ & Grid & 21,40 \\
\hline 28 & 225 & 0.2 & 60 & 100 & 50 & $100 \%$ & lines & 24,60 \\
\hline 29 & 225 & 0.2 & 60 & 100 & 50 & $100 \%$ & Triangles & 21,40 \\
\hline 30 & 225 & 0.2 & 60 & 100 & 50 & $100 \%$ & $\begin{array}{c}\text { Tri } \\
\text { Hexagon }\end{array}$ & 21,10 \\
\hline 31 & 225 & 0.2 & 60 & 100 & 50 & $100 \%$ & Cubic & 23,00 \\
\hline 32 & 225 & 0.2 & 60 & 100 & 50 & $100 \%$ & $\begin{array}{c}\text { Cubic } \\
\text { Subdivisio } \\
n\end{array}$ & 20,30 \\
\hline 33 & 225 & 0.2 & 60 & 100 & 50 & $100 \%$ & Octet & 22,20 \\
\hline 34 & 225 & 0.2 & 60 & 100 & 50 & $100 \%$ & $\begin{array}{l}\text { Quarter } \\
\text { Qubic }\end{array}$ & 21,80 \\
\hline 35 & 225 & 0.2 & 60 & 100 & 50 & $100 \%$ & Concentric & 31,30 \\
\hline 36 & 225 & 0.2 & 60 & 100 & 50 & $100 \%$ & Zig Zag & 24,60 \\
\hline 37 & 225 & 0.2 & 60 & 100 & 50 & $100 \%$ & Cross & 19,10 \\
\hline 38 & 225 & 0.2 & 60 & 100 & 50 & $100 \%$ & Cross 3D & 20,00 \\
\hline 39 & 225 & 0.2 & 60 & 100 & 50 & $100 \%$ & Gyroid & 26,00 \\
\hline
\end{tabular}

\section{Hasil dan Pembahasan}

Hal yang harus dilakukan dalam menetukan hasil dari pengujian adalah dapat melakukan analisa data yang diperoleh berdasarkan tahapan-tahapan yang telah dilakukan. Dari hasil yang diperoleh setelah dilakukannya pengujian tarik pada 
spesimen uji, maka akan didapatkan nilai kekuatan tarik yang bervariasi sesuai dengan parameter-parameter yang telah ditentukan berdasarkan eksperimen tersebut. Adapun parameter tersebut dengan geometri yaitu nozzle temperature $\left(205^{\circ} \mathrm{C}, 215{ }^{\circ} \mathrm{C}, 225^{\circ} \mathrm{C}\right)$, layer Thickness $0,2 \mathrm{~mm}$, bed temperature $60^{\circ} \mathrm{C}$, travel Speed $100 \mathrm{~mm} / \mathrm{s}$, printing Speed 50 $\mathrm{mm} / \mathrm{s}$, infill precentase 100\% dan infill type (Grid, Lines, Triangles, Tri Hexagon, Cubic, Cubic Subdivision, Octet, Quarter Qubic, Concentric, Zig Zag, Cross, Cross 3D dan Gyroid).

Berdasarkan hasil diperoleh dari data pengujian selanjutnya akan dilakukan pengolahan data dalam bentuk grafik yang ditunjukkan Gambar 4, parameter dan bentuk geometri infill dan nozzle temperature memiliki pengaruh besar terhadap kekuatan tarik spesimen uji, sehingga dari hasil pengujian nilai pengujian tertinggi dan terendah pada setiap temperatur spesimen dapat diketahui. Hasil kekuatan tarik tertinggi untuk material PLA+ Sugoi yaitu nozzle temperature $205^{\circ} \mathrm{C}$ pada Infill type Concentric yaitu $32,40 \mathrm{MPa}$, nozzle temperature $215^{\circ} \mathrm{C}$ pada infill Concentric $31,70 \mathrm{MPa}$ dan nozzle temperature $225^{\circ} \mathrm{C}$ pada infill Concentric $31,30 \mathrm{Mpa}$. Untuk hasil kekuatan tarik terendah nozzle temperature $205^{\circ} \mathrm{C}$ diperoleh pada Infill type Cross yaitu $19,40 \mathrm{MPa}$, nozzle temperature $215^{\circ} \mathrm{C}$ pada infill Cross $19,80 \mathrm{MPa}$ dan nozzle temperature $225^{\circ} \mathrm{C}$ pada infill Cross $19,10 \mathrm{MPa}$.

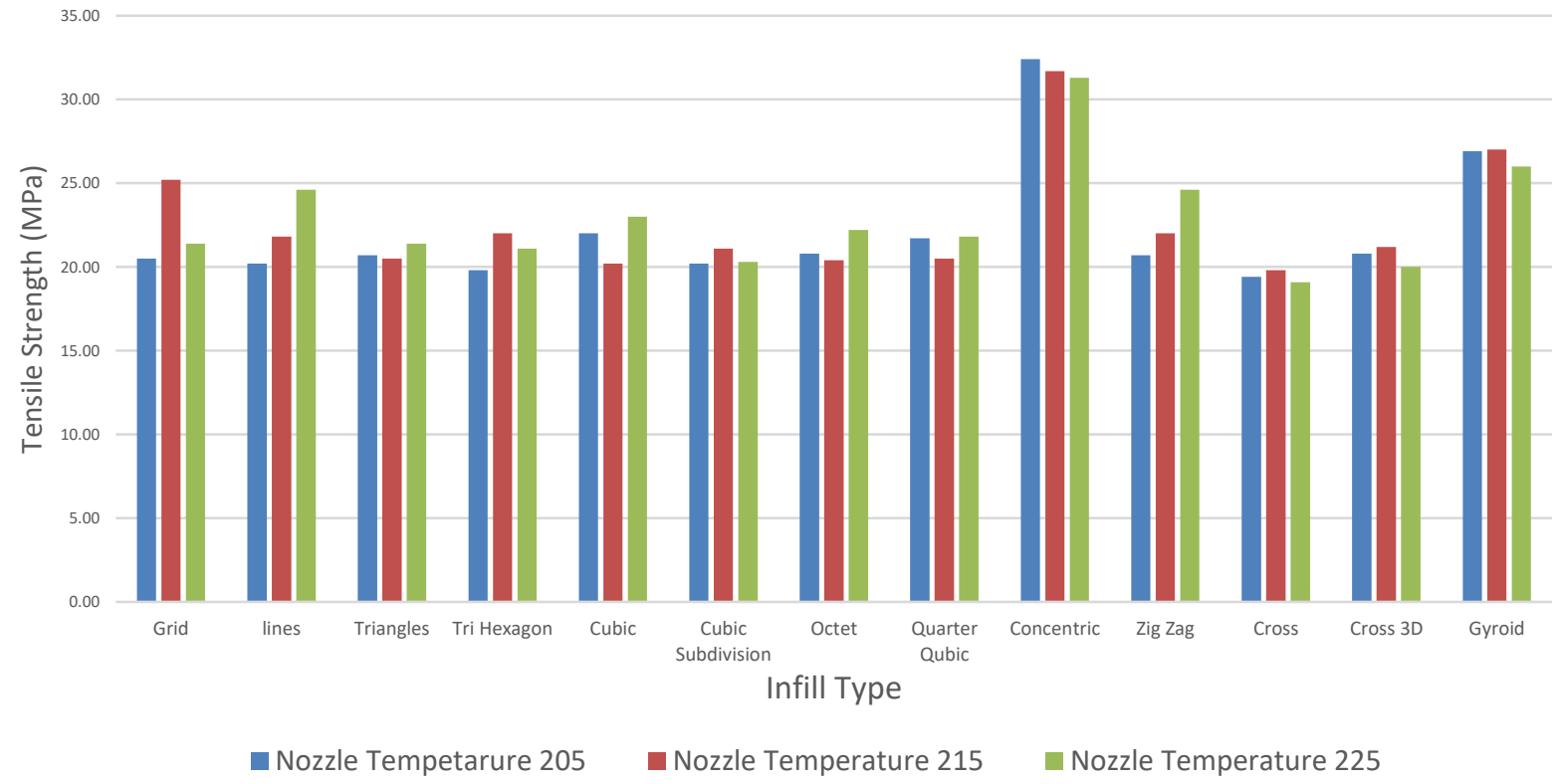

Gambar 4. Grafik Hasil Uji Tarik Spesimen Uji

\section{Kesimpulan}

Dari pembahasan yang telah dilakukan pada tahapan pengujian dan analisa, maka dapat ditarik kesimpulan bahwa nilai kekuatan tarik tertinggi pada setiap temperatur yang ditentukan hasil yang diperoleh dominan pada geometri Infill type concentric yaitu terdapat pada spesimen uji ke 9 yaitu 32,40 MPa dengan parameter nozzle temperature $205{ }^{\circ} \mathrm{C}$, layer thickness $0,2 \mathrm{~mm}$, bed temperature $60^{\circ} \mathrm{C}$, travel speed $100 \mathrm{~mm} / \mathrm{s}$, printing speed $50 \mathrm{~mm} / \mathrm{s}$ dan infill precentase 100\%, sedangkan nilai kekuatan tarik terendah terdapat geometri infill type cross pada spesimen uji ke 37 yaitu 19,70 MPa dengan parameter nozzle temperature $225^{\circ} \mathrm{C}$, layer Thickness $0,2 \mathrm{~mm}$, bed temperature $60^{\circ} \mathrm{C}$, travel speed 100 $\mathrm{mm} / \mathrm{s}$, printing speed $50 \mathrm{~mm} / \mathrm{s}$ dan infill precentase $100 \%$. 


\section{Daftar Pustaka}

[1] Tuan D. Ngo., Alireza Kashani, Gabriele Imbalzano, Kate T. Q. Nguyen \& David Hui. 2018. Additive manufacturing (3D printing): A review of materials, methods, applications and challenges. Jurnal Composite Part B: engineering.

[2] Sood, A. K., Ohdar, R. K. and Mahapatra, S. S., (2009), Improving dimensional accuracy of Fused Deposition Modelling processed part using grey Taguchi method, Materials and Design. Elsevier Ltd, 30(10), pp. 4243-4252. doi: 10.1016/j.matdes.2009.04.030.

[3] Satyanarayana, B, and Prakash, KJ 2015, Component Replication using 3D Printing Technology. Procedia Materials Science 10., p.263 - 269.

[4] Babagowda, R. S. Kadadevara Math, R. Goutham, and K. R. Srinivas Prasad, "Study of Effects on Mechanical Properties of PLA Filament which is blended with Recycled PLA Materials,” IOP Conf. Ser. Mater. Sci. Eng., vol. 310, no. 1, 2018.

[5] D. Sulayman, "Pengaruh Suhu dari Heater Nozzle Terhadap Produk Printer 3D," Universitas Muhammadiyah Surakarta, 2015.

[6] Z. Quan et al., "Printing Direction Dependence of Mechanical Behavior of Additively Manufactured 3D Preforms and Composites," Compos. Struct., Vol. 184, pp. 917-923, 2018.

[7] Ziemian C, et al., Anisotropic mechanical properties of ABS parts fabricated by fused deposition modelling. In: Gokcek M, editor. Mechanical engineering, InTech, 159-180, 2012.

[8] Aboma Wagari Gebisa \& Hirpa G. Lemu, Influence of 3D Printing FDM Process Parameters on Tensile Property of ULTEM 9085, Procedia Manufacruring 30, 331-338, 2018.

[9] Lubis, S., Djamil, S. \& Yolanda, Y.,. Pengaruh Orientasi Objek Pada Proses 3d Printing Bahan Polymer Pla Dan Abs Terhadap Kekuatan Tarik Dan Ketelitian Dimensi Produk. Sinergi, 20(1), p.27, 2016.

[10] Z. S. Suzen, Hasdiansah, \& Yuliyanto, Pengaruh Tipe Infill Dan Temperatur Nozzle Terhadap Kekuatan Tarik Produk 3d Printing Filamen Pla+ Esun, Manutech, Vol. 12, No. 02, 2020.

[11] Christiliana, M., Pristiansyah, Oktriadi Y. Optimasi Parameter Proses pada 3D Printing FDM terhadap Akurasi Dimensi Filament PLA Food Grade. Manutech [Internet]. 2021Jun.18 [cited 2021Jul.27]; 13(01):1-8.

[12] Hasdiansah, Yudha Bika Pratama, Pristiansyah. Pengaruh Parameter Proses Slicing Software Terhadap Kekasaran Permukaan Printing Part Filamen ST-PLA: Pengaruh Parameter Proses Slicing Software Terhadap Kekasaran Permukaan Printing Part Menggunakan Filamen ST-PLA. Manutech [Internet]. 2021Jun.18 [cited 2021Jul.27];13(01):33-40

[13] Son TA, Minh PS, Thanh TD. Effect of 3D Printing Parameters on the Tensile Strength of Products. Key Engineering Materials [Internet]. Trans Tech Publications, Ltd.; 2020 Sep;863:103-8.

[14] Triyono J, Sukanto H, Saputra R, Smaradhana D. The effect of nozzle hole diameter of 3D printing on porosity and tensile strength parts using polylactic acid material. Open Engineering. 2020;10(1): 762-768.

[15] Kiński W, Pietkiewicz P. Influence of the Printing Nozzle Diameter on Tensile Strength of Produced 3D Models in FDM Technology. Agricultural Engineering. 2020;24(3): 31-38.

[16] https://the3dbros.com/3d-print-infill-patterns-explained/ (diakses: 15 Agustus 2021) 